\title{
An Index for Estimating the Stability of the Layered Rock Masses under Excavation Disturbance
}

\author{
Ding-ping Xu $\mathbb{D}^{1,2}$ Gong-kai Gu, ${ }^{3}$ Liang-peng Wan, ${ }^{3}$ Dong-fang Chen, ${ }^{4}$ \\ and Shu-ling Huang ${ }^{5}$ \\ ${ }^{1}$ State Key Laboratory of Geomechanics and Geotechnical Engineering, Institute of Rock and Soil Mechanics, \\ Chinese Academy of Sciences, Wuhan 430071, China \\ ${ }^{2}$ Guangxi Key Laboratory of Geomechanics and Geotechnical Engineering, Guilin University of Technology, Guilin 430071, China \\ ${ }^{3}$ Wudongde Project Construction Department, China Three Gorges Projects Development Co., Ltd., Kunming 541004, China \\ ${ }^{4}$ School of Resources and Environmental Engineering, Wuhan University of Technology, Wuhan 430070, China \\ ${ }^{5}$ Key Laboratory of Geotechnical Mechanics and Engineering of Ministry of Water Resources, \\ Yangtze River Scientific Research Institute, Wuhan 430010, China
}

Correspondence should be addressed to Ding-ping Xu; dpxu@whrsm.ac.cn

Received 6 March 2018; Accepted 7 June 2018; Published 8 July 2018

Academic Editor: Paweł Kłosowski

Copyright (C) 2018 Ding-ping Xu et al. This is an open access article distributed under the Creative Commons Attribution License, which permits unrestricted use, distribution, and reproduction in any medium, provided the original work is properly cited.

The mechanical behaviours of layered rock mass exhibit significant differences in the directions parallel and vertical to the bedding planes. The deformation and failure of a layered rock mass has remarkable weak-plane dependence, which brings a major challenge to the control of the stability of the surrounding rock mass in underground openings. In this study, a layered rock mass is firstly regarded as a composite material composed of interlayered rocks and bedding planes. Then, based on the Mohr-Coulomb and maximum tensile stress criteria, an index of point safety factor for a layered rock mass is established considering the mechanical properties of interlayered rocks and bedding planes. The safety of the artificial layered rock mass specimens in the triaxial test is evaluated using this index. The results show that the distribution of this index is in good agreement with the macroscopic failed zone of the rock specimen, indicating that this index is feasible for characterizing the macroscopic failure of rock masses. Finally, the index is adopted to evaluate the stability of the midpartition between the \#3 and \#4 diversion tunnels at the right bank of the Wudongde hydropower station before and after its reinforcement. The results indicate that there is a yielded zone where the point safety factor is less than 1.0 in the unreinforced midpartition of the collapsed tunnel section, and it is nearly connected. If it is not reinforced in time, collapse cut-through of the entire midpartition may occur and then endanger the overall stability of the tunnel. After the emergency reinforcement measure with two-ended anchored piles and concrete backfill, the safety of the midpartition is significantly improved. In this case, the safety factor is much larger than 1.0, indicating that the adoption of this emergency reinforcement measure is effective.

\section{Introduction}

Layered rock masses are geologic bodies with close relationships with human engineering activities, accounting for more than $70 \%$ of the shallow parts of Earth's crust. They exhibit obvious transversely isotropic mechanical characteristics due to their significantly different mechanical properties in the directions parallel and vertical to the bedding planes. They exhibit appreciable deformation anisotropy, excavation damage deterioration, and weak-plane dependence of the failure under excavation disturbance, which results in major challenges to the control of the stability of the surrounding rock mass of the underground openings within them.

To control the stability of the surrounding rock mass, their safety conditions should first be identified. Normally, some testing instruments (such as multipoint extensometers, hollow inclusion stress gauges, and ultrasonic testing detectors) are often used to monitor and track the mass deformation, stress distribution, and excavation damage zone 
of the surrounding rock. However, due to economic costs and technical limitations, the response information of the rock mass excavation obtained by these testing methods often lacks representativeness and comprehensiveness. That is, it only represents the response of the rock mass excavation at the measuring point, in the section, or within the space near the measuring point. To accurately evaluate the safety of the surrounding rock mass, further studies need to be conducted using other methods on this basis. The numerical modelling method based on dynamic feedback of on-site monitoring information is one of the most effective means of solving such a dilemma. However, the output of the numerical modelling method usually comes from the perspective of computational mechanics, and understanding and effective utilization requires a theoretical basis in mathematics, mechanics, and engineering geology, as well as engineering experience, which undoubtedly increases the threshold of its practical application. Therefore, an important problem for promoting the popularization and application of numerical modelling methods in geotechnical engineering is how to convey the output from numerical modelling to designers, constructors, and supervisors in a more straightforward way. As a widely accepted safety index in the engineering field, various safety factors establish a bridge between numerical modelling and the safety state of an engineering rock mass. For example, Kou et al. [1] used a point safety factor based on the Drucker-Prager strength criterion to analyse the stability of high and steep slopes of the Three Gorges ship lock. Yang et al. [2] defined the point safety factor as the ratio of unit shear strength to shear stress in the parallel direction on a slip plane and used it to analyse the spatial sliding mechanism of a slope. Li et al. [3] employed the Mohr-Coulomb and Drucker-Prager strength criteria to establish a unit-based safety factor, which was used to determine the unstable zone of the surrounding rock mass. Lin et al. [4] presented a danger factor based on the Mohr-Coulomb criterion (the reciprocal of the conventional safety factor), to indicate how far the material was from a failure state. Zhang et al. [5] derived a yield approach index to describe the damage of excavation disturbed zones based on the interaction relationship between the yield surface and the nonyield stress point in the principal stress space. Goel et al. [6] adopted a point safety factor based on the Sheorey criterion to determine the bolt length requirement in underground openings. Kumar et al. [7] defined the safety factor as the ratio of the strength estimated by the Hoek-Brown criterion and the stress induced on a pillar to evaluate the safety of the pillar. Wang et al. [8] utilized a dilatancy safety factor based on the Van Sambeek criterion to evaluate the safety of salt caverns.

In general, the above point safety indices were established based on the assumption of isotropic geotechnical materials without considering the anisotropy of the mechanical properties of the rock mass in this study, that is, the layered rock mass. These indices cannot accurately characterize the safety state of layered rock masses under excavation disturbance because the layered rock mass is a typical transversely isotropic material. Its excavation response is controlled by the mechanical properties of

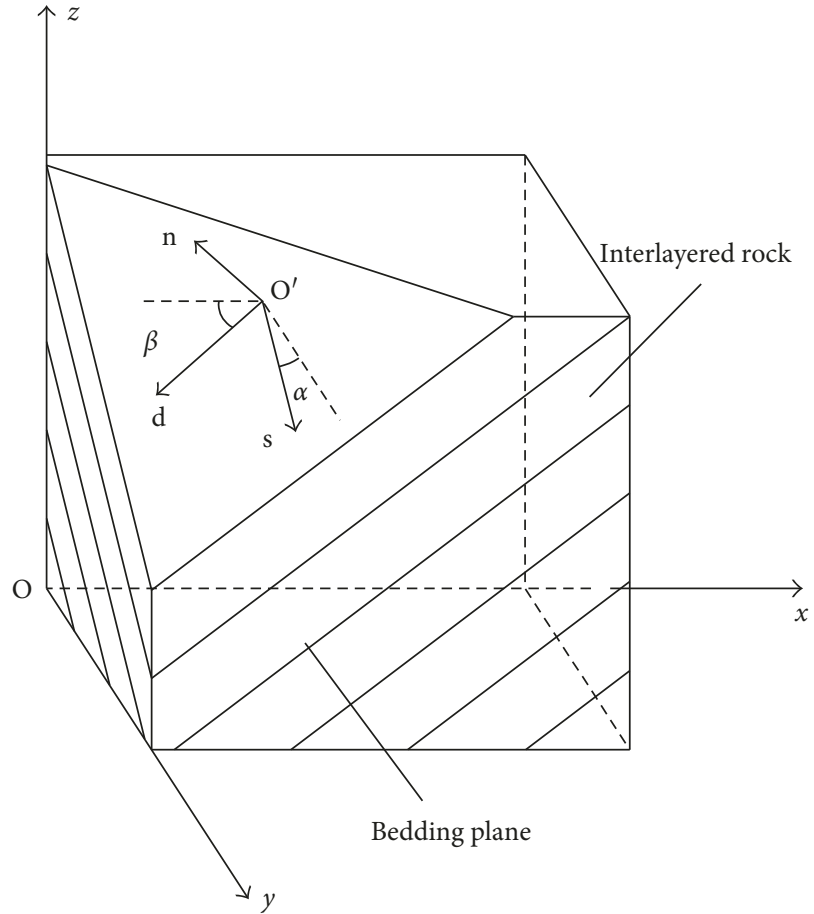

FIgURE 1: Coordinate system for a layered rock mass. The local coordinate system is defined by bedding plane dip direction d, strike direction $\mathrm{s}$, and normal direction $\mathrm{n}$, and the global coordinate system consists of east direction $x$, north direction $y$, and up direction $z$.

bedding planes and interlayered rocks, and they are constrained by the relationship between the free face and the occurrence of bedding planes.

This paper proposes a point safety factor for layered rock masses, which takes the mechanical properties of interlayered rocks and bedding planes into account synthetically, to address the issue concerning the safety assessment of a layered rock mass under excavation disturbance. The suitability of the index is verified by comparing the numerical predictions with the actual stability of the midpartition between the \#3 and \#4 diversion tunnels at the right bank of the Wudongde hydropower station before and after its reinforcement.

\section{Point Safety Factor of a Layered Rock Mass}

2.1. Description of Coordinates and Mechanical Model. A layered rock mass is regarded as a composite material of interlayered rocks and bedding planes. Based on the linear Mohr-Coulomb criterion and the maximum tensile stress criterion, the mechanical models for interlayered rocks and bedding planes are established in the global coordinate system and local coordinate system, respectively (Figure 1). Then, they are synthesized to obtain an elastic-plastic model, the Aniso-soft model [9] for a layered rock mass, which considers strength and deformation with transverse isotropy. The model is essentially an equivalent continuum model with consideration of the strength and deformation anisotropy of layered rock masses. The specific geometric 


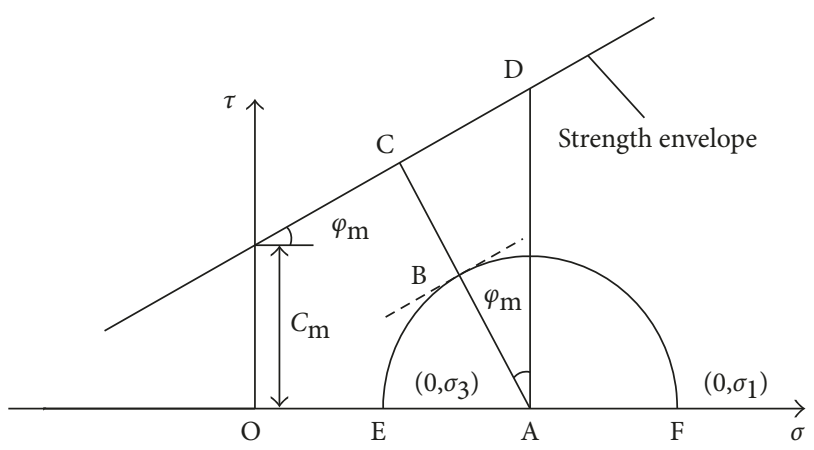

Figure 2: Stress state and the Mohr-Coulomb strength envelope under the global coordinate system.

parameters (such as bedding plane strike $\alpha$ and dip angle $\beta$ ) and strength parameters (such as bedding plane cohesion and friction angle) can reflect the mechanical properties of the bedding plane, and there is no need to construct a contact interface or solid element in the mesh model to simulate the properties of the bedding plane.

\subsection{Point Safety Factor of a Layered Rock Mass}

2.2.1. Point Safety Factor of Interlayered Rock. The stress state of the interlayered rock is determined by the stress state in the global coordinate system. The point safety factor for the shear failure of the interlayered rock $\left(\mathrm{Fos}_{\mathrm{m}}^{\mathrm{s}}\right)$ is defined based on the spatial stress state and the position relationship of the Mohr-Coulomb shear envelope (Figure 2):

$$
\begin{aligned}
\text { Fos }_{\mathrm{m}}^{\mathrm{s}} & =\frac{|\mathrm{AC}|}{|\mathrm{AB}|}=\frac{|\mathrm{AD}| \cos \varphi_{\mathrm{m}}}{|\mathrm{AB}|} \\
& =\left(2 c_{\mathrm{m}}+\left(\sigma_{1}+\sigma_{3}\right) \tan \varphi_{\mathrm{m}}\right) \frac{\cos \varphi_{\mathrm{m}}}{\left(\sigma_{1}-\sigma_{3}\right)},
\end{aligned}
$$

where $c_{\mathrm{m}}$ is the cohesion of the interlayered rock, $\varphi_{\mathrm{m}}$ is the internal friction angle of the interlayered rock, and $\sigma_{1}$ and $\sigma_{3}$ are the maximum principal stress and the minimum principal stress, respectively.

The point safety factor for the tensile failure of the interlayered rock $\left(\operatorname{Fos}_{\mathrm{m}}^{\mathrm{t}}\right)$ is the ratio of the tensile strength $\left(\sigma_{\mathrm{m}}^{\mathrm{t}}\right)$ to the maximum tensile stress. It can be defined by the following equation:

$$
\operatorname{Fos}_{\mathrm{m}}^{\mathrm{t}}=\frac{\sigma_{\mathrm{m}}^{\mathrm{t}}}{\sigma_{3}} .
$$

The minimum value between Fos $_{\mathrm{m}}^{\mathrm{s}}$ and Fos $\mathrm{s}_{\mathrm{m}}^{\mathrm{t}}$ is selected to be the point safety factor of the interlayered rock $\left(\mathrm{Fos}_{\mathrm{m}}\right)$, which is expressed by the following equation:

$$
\operatorname{Fos}_{\mathrm{m}}=\min \left(\operatorname{Fos}_{\mathrm{m}}^{\mathrm{s}}, \operatorname{Fos}_{\mathrm{m}}^{\mathrm{t}}\right) \text {. }
$$

2.2.2. Point Safety Factor of a Bedding Plane. The stress state of a bedding plane is determined by the stress state in the local coordinate system that is defined by the occurrence of bedding planes. The point safety factor for the shear failure of a bedding plane is defined as follows:

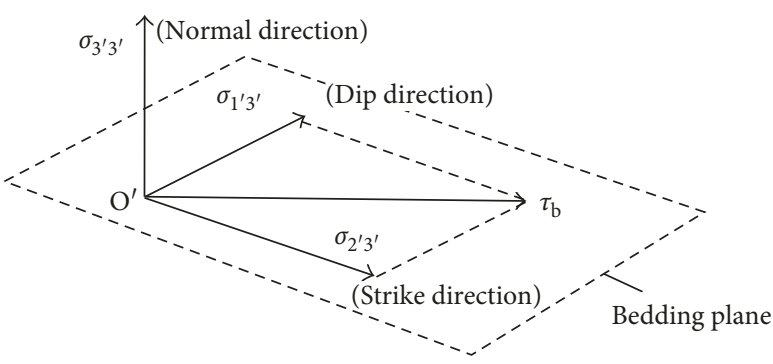

FIGURE 3: Stress components on a bedding plane.

$$
\operatorname{Fos}_{\mathrm{b}}^{\mathrm{s}}=\frac{\left(c_{\mathrm{b}}+\sigma_{\mathrm{b}}^{n} \tan \varphi_{\mathrm{b}}\right)}{\tau_{\mathrm{b}}}
$$

where $c_{\mathrm{b}}$ denotes the cohesion of the bedding plane, $\varphi_{\mathrm{b}}$ denotes the internal friction angle of the bedding plane, and $\tau_{\mathrm{b}}$ and $\sigma_{\mathrm{b}}^{\mathrm{n}}$ denote the shear stress and normal stress on the bedding plane, respectively, and their values are determined by the stress component in the local coordinate system of the bedding plane obtained from the following equation:

$$
\sigma_{i^{\prime} j^{\prime}}=R \sigma_{i j} R^{T},
$$

where $\sigma_{i j}(i, j=1,2,3)$ denotes the stress component in the global coordinate system, $\sigma_{i^{\prime} j^{\prime}}\left(i^{\prime}, j^{\prime}=1,2,3\right)$ denotes the stress component in the local coordinate system of the bedding plane, $R$ denotes the stress transformation matrix, and $R^{T}$ denotes its transposed matrix. The specific expression for $R$ is as follows:

$$
R=\left[\begin{array}{ccc}
\cos \alpha & \sin \alpha & 0 \\
\cos \alpha \cos \beta & \sin \alpha \cos \beta & \sin \beta \\
\cos \alpha \sin \beta & \cos \alpha \sin \beta & \cos \beta
\end{array}\right] .
$$

After obtaining the stress component in the local coordinate system of the bedding plane, the following equation is established according to the stress relation graph as shown in Figure 3:

$$
\begin{aligned}
\tau_{\mathrm{b}} & =\sqrt{\left(\sigma_{1^{\prime} 3^{\prime}}\right)^{2}+\left(\sigma_{2^{\prime} 3^{\prime}}\right)^{2}}, \\
\sigma_{\mathrm{b}}^{\mathrm{n}} & =\sigma_{3^{\prime} 3^{\prime}} .
\end{aligned}
$$

The point safety factor for the tensile failure of the bedding plane $\left(\operatorname{Fos}_{\mathrm{b}}^{\mathrm{t}}\right)$ is the ratio of the tensile strength $\left(\sigma_{\mathrm{b}}^{\mathrm{t}}\right)$ to the maximum tensile stress on the bedding plane, as denoted by the following equation:

$$
\operatorname{Fos}_{\mathrm{b}}^{\mathrm{t}}=\frac{\sigma_{\mathrm{b}}^{\mathrm{t}}}{\sigma_{3^{\prime} 3^{\prime}}},
$$

The minimum value between $\operatorname{Fos}_{\mathrm{b}}^{\mathrm{s}}$ and $\operatorname{Fos}_{\mathrm{b}}^{\mathrm{t}}$ is selected to be the point safety factor of the bedding plane $\left(\mathrm{Fos}_{\mathrm{b}}\right)$, which is expressed by the following equation:

$$
\operatorname{Fos}_{\mathrm{b}}=\min \left(\operatorname{Fos}_{\mathrm{b}}^{\mathrm{s}}, \operatorname{Fos}_{\mathrm{b}}^{\mathrm{t}}\right)
$$

2.2.3. Point Safety Factor of a Layered Rock Mass. Due to the fact that a rock mass always fails along or across its weakest 
component, the minimum value between Fos ${ }_{\mathrm{m}}$ and Fos $\mathrm{b}_{\mathrm{b}}$ is selected to be the point safety factor of the layered rock mass, which is shown as follows:

$$
\text { Fos }=\min \left(\text { Fos }_{\mathrm{m}}, \text { Fos }_{\mathrm{b}}\right) \text {. }
$$

According to (1)-(10), the point safety factor of the layered rock mass is implemented in FLAC3D using the Fish language [10], and it is combined with the Aniso-soft model. The index considers that when its value is less than 1.0, the layered rock mass is in a yielding state and needs to be reinforced; when its value is greater than 1.0, the layered rock mass is in a safe state. Note that the yield of a rock mass does not mean failure, that is, Fos $=1.0$ does not indicate the failure of the rock mass. Therefore, when using this index isoline to mark the boundary of the failed zone in rock masses, a threshold smaller than 1.0 should be selected. In practice, the selection of the threshold of Fos to mark the extent of the failed zone is a risky decision as this leads to a conservative or an unsafe reinforcement design against rock mass instability. The threshold is set to be 0.9 in the engineering application case by comparing the isolines for the point safety factor and the collapse outline of the rock mass around the tunnel (Section 4.1).

\section{Verification of Laboratory Test Results}

Based on the mechanical parameters of the artificial layered rock mass specimen provided by Tien et al. [11], the Anisosoft model is employed to carry out a numerical simulation of the compression under different confining pressures. The mechanical parameters of the artificial layered rock mass specimen (cylinder specimen with a diameter of $5 \mathrm{~cm}$ and a height of $10 \mathrm{~cm}$ ) from laboratory tests are shown in Table 1.

Figure 4 is the point safety factor, plastic zone, and actual failure of a layered rock mass specimen with bedding planes at $\beta=60^{\circ}$ under different confining pressures. It can be observed from the figure that, at the confining pressures of 0 and $35 \mathrm{MPa}$, a long and narrow zone where the point safety factor is less than 1.0 cuts through the geometrical centre of the specimen and has a dip angle similar to that of the bedding planes. This indicates that the failure of the specimen with bedding planes at $\beta=60^{\circ}$ is controlled by its bedding plane, and it fails along a bedding plane across the centre, which is in good agreement with the actual failure of the specimen. Although the plastic zone distribution can give the yielded zone of the specimen, it cannot give the safety degree of the yielded zone, resulting in the failure to divide the failed zone from the yielded zone. This indicates that, under the same conditions, the point safety factor method can evaluate the safety degree of the artificial layered rock mass specimens more directly and effectively than the plastic zone method.

\section{An Engineering Application Case}

4.1. Engineering Background. The Wudongde hydropower station is the upper cascade among four hydropower cascades: the Wudongde, Baihetan, Xiluodu, and Xiangjiaba stations in the lower reaches of the Jinsha River. The station has a 10,200 MW power plant installed, and the annual average generated energy is 40.11 billion $\mathrm{kW} \cdot \mathrm{h}$. Five diversion tunnels are arranged on the left and right banks of the hydropower station (\#1 and \#2 diversion tunnels on the left bank and \#3 to \#5 diversion tunnels on the right bank, as shown in Figure 5). The entrance floor elevation of the \#1 and \#2 diversion tunnels is $814 \mathrm{~m}$, and the exit elevation is $800 \mathrm{~m}$. The excavation body is in a city-gate shape with net cross-sectional dimensions of approximately $18 \mathrm{~m} \times 26 \mathrm{~m}$ (width $\times$ height). The entrance floor elevation of the $\# 3$ and \#4 diversion tunnels is $812 \mathrm{~m}$, the exit floor elevation is $800 \mathrm{~m}$, and the net cross-sectional dimensions are approximately $20 \mathrm{~m} \times 27.5 \mathrm{~m}$. The entrance floor elevation of the \#5 diversion tunnel is $833 \mathrm{~m}$, the exit elevation is $824 \mathrm{~m}$, and the net cross-sectional dimensions are approximately $15 \mathrm{~m} \times 19 \mathrm{~m}$. The diversion tunnels are arranged in parallel, with an axis spacing of $50 \mathrm{~m}$ and a midpartition thickness of 32-35 $\mathrm{m}$ between the tunnels.

The statistical analysis of the geologic conditions appearing in the excavation shows that the rock mass of the upper reaches of the diversion tunnel on the right bank is thin and extremely thin-layered marble dolomite, whose length in the \#3 diversion tunnel is approximately $1,009.5 \mathrm{~m}$, accounting for $68.6 \%$ of the total length. The length of thin and extremely thin-layered marble dolomite in the \#4 diversion tunnel is approximately $1,187 \mathrm{~m}$, accounting for $73.6 \%$ of the total length, and that of the \#5 diversion tunnel is approximately $1,244.6 \mathrm{~m}$ in length, accounting for $72.9 \%$ of the total length. During excavation, local failures (such as collapse or falling) and insufficient supporting strength are prone to occur in the surrounding rock mass, which pose a serious threat to construction safety. When excavating the 4th layer of the tunnel section between stakes $\mathrm{K} 1+230$ and $\mathrm{K} 1+270$ in the \#3 diversion tunnel, a large-scale collapse with an amount of $3500 \mathrm{~m}^{3}$ (Figure 6) occurred because the construction of systematic bolts $(6 \mathrm{~m}$ and $9 \mathrm{~m}$ fully grouted bolts arranged in quincunx with a row spacing of $1.25 \mathrm{~m}$ and a column spacing of $1.25 \mathrm{~m}$ ) was delayed by 35 days due to construction organization. According to the collapse morphology and geologic records during excavation, the emergency expert group repeatedly analysed the geologic conditions and the causes of collapse. Based on the initial support design (9 $\mathrm{m}$ fully grouted bolts arranged in quincunx with a row spacing of $1.0 \mathrm{~m}$ and a column spacing of $1.0 \mathrm{~m}$ ), an emergency reinforcement measure with twoended anchored piles and concrete backfill was proposed, as shown in Figure 7.

4.2. Calculation Model and Initial Stress. The 3D model was established in accordance with the actual step excavation and geometry of the collapsed tunnel section, as shown in Figure 8(a). The support structure model which includes fully grouted bolts and anchored piles was established in terms of the actual support parameters, as shown in Figure 8(b). The cable element in FLAC3D [10] was employed for simulating fully grouted bolts and anchored piles. The parameters 
TABLE 1: Mechanical parameters of the artificial layered rock mass.

\begin{tabular}{ccccccccccccccccc}
\hline$E_{1}(\mathrm{GPa})$ & $E_{3}(\mathrm{GPa})$ & $G_{13}(\mathrm{GPa})$ & $\nu_{12}$ & $\nu_{13}$ & $\psi_{\mathrm{m}}\left({ }^{\circ}\right)$ & $\sigma_{\mathrm{m}}^{\mathrm{t}}(\mathrm{MPa})$ & $c_{\mathrm{m}}(\mathrm{MPa})$ & $\varphi_{\mathrm{m}}\left({ }^{\circ}\right)$ & $\beta\left(^{\circ}\right)$ & $\alpha\left(^{\circ}\right)$ & $c_{\mathrm{b}}(\mathrm{MPa})$ & $\varphi_{\mathrm{b}}\left({ }^{\circ}\right)$ & $\psi_{\mathrm{b}}\left(\left(^{\circ}\right)\right.$ & $\sigma_{\mathrm{b}}^{\mathrm{t}}(\mathrm{MPa})$ \\
\hline 5.26 & 4.58 & 1.96 & 0.21 & 0.23 & 10 & 2.4 & 20 & 45 & 60 & 0 & 11 & 18 & 6 & 0.5 \\
\hline
\end{tabular}

Note: $E_{1}$ and $E_{3}$ denote the elastic moduli in the directions parallel and normal to the bedding plane, respectively; $G_{13}$ denotes the shear modulus in the direction normal to the bedding plane, which is calculated based on the empirical equation $G_{13}=E_{1} E_{3} /\left(E_{1}\left(1+2 v_{13}\right)+E_{3}\right)$ [12]; $v_{12}$ and $v_{13}$ denote the Poisson ratios in the directions parallel and normal to the bedding plane, respectively; $\psi$ and $\psi_{j}$ denote the dilation angles of the interlayered rock and the bedding plane, respectively.
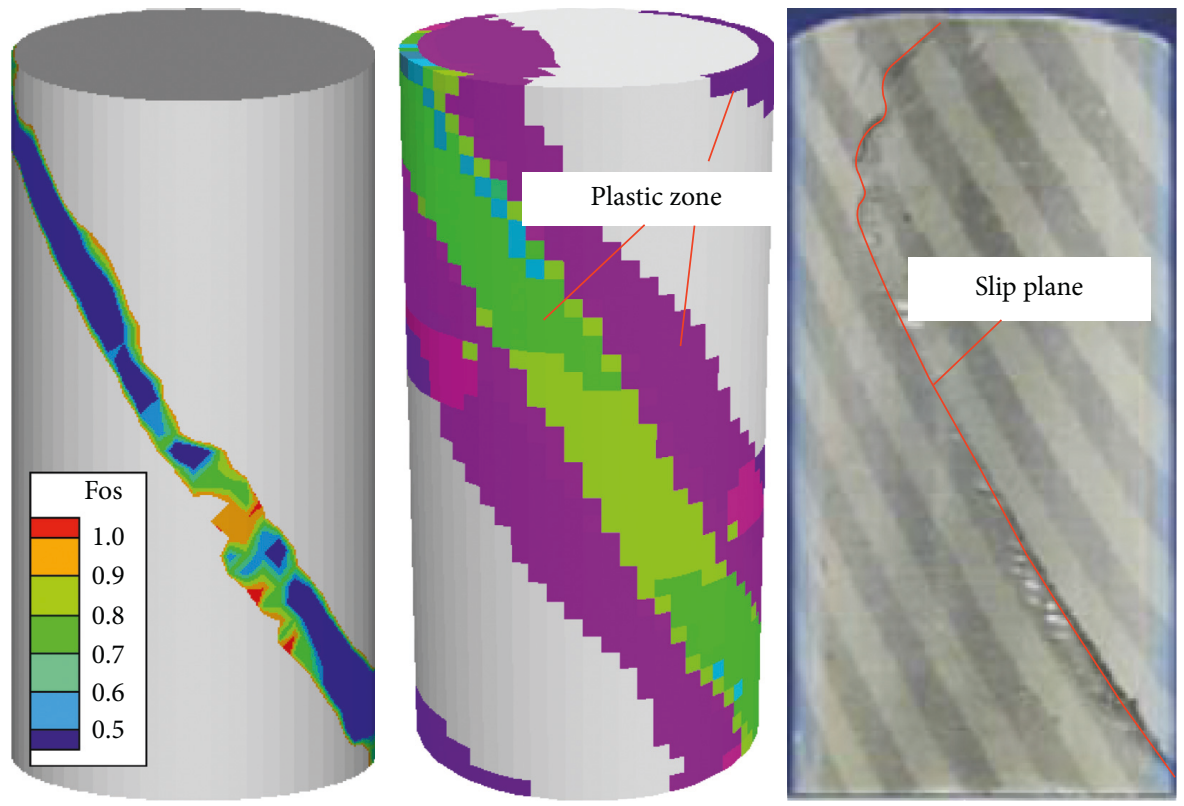

(a)
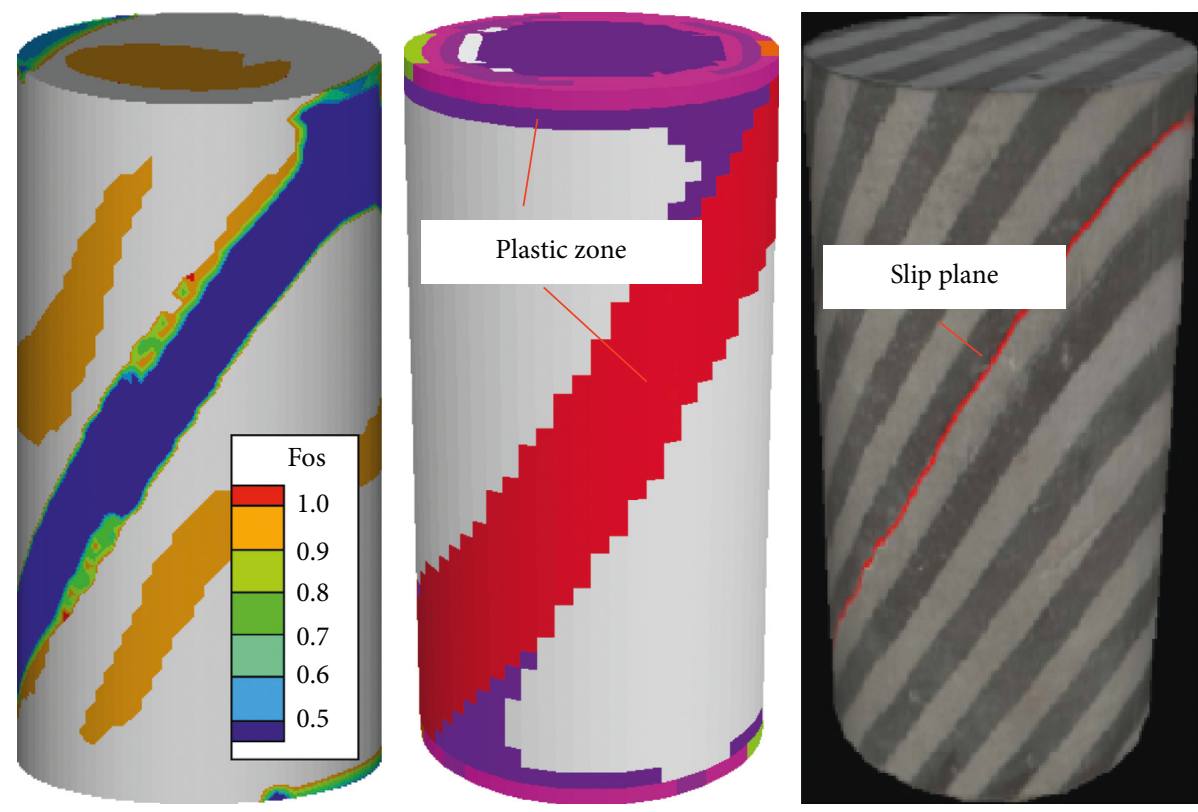

(b)

Figure 4: Point safety factor, plastic zone, and actual failure of the artificial layered rock mass specimen: (a) $\beta=60^{\circ}$ and confining pressure $0 \mathrm{MPa}$ and (b) $\beta=60^{\circ}$ and confining pressure $35 \mathrm{MPa}$.

of fully grouted bolt and anchored pile are shown in Table 2. The collapse body and its position in the 3D mesh model are shown in Figure 9.
The initial stress was determined according to in situ stress measurement. The vertical stress was approximately 7.56 MPa, and the horizontal lateral stresses in the $x$ - and $y$ - 


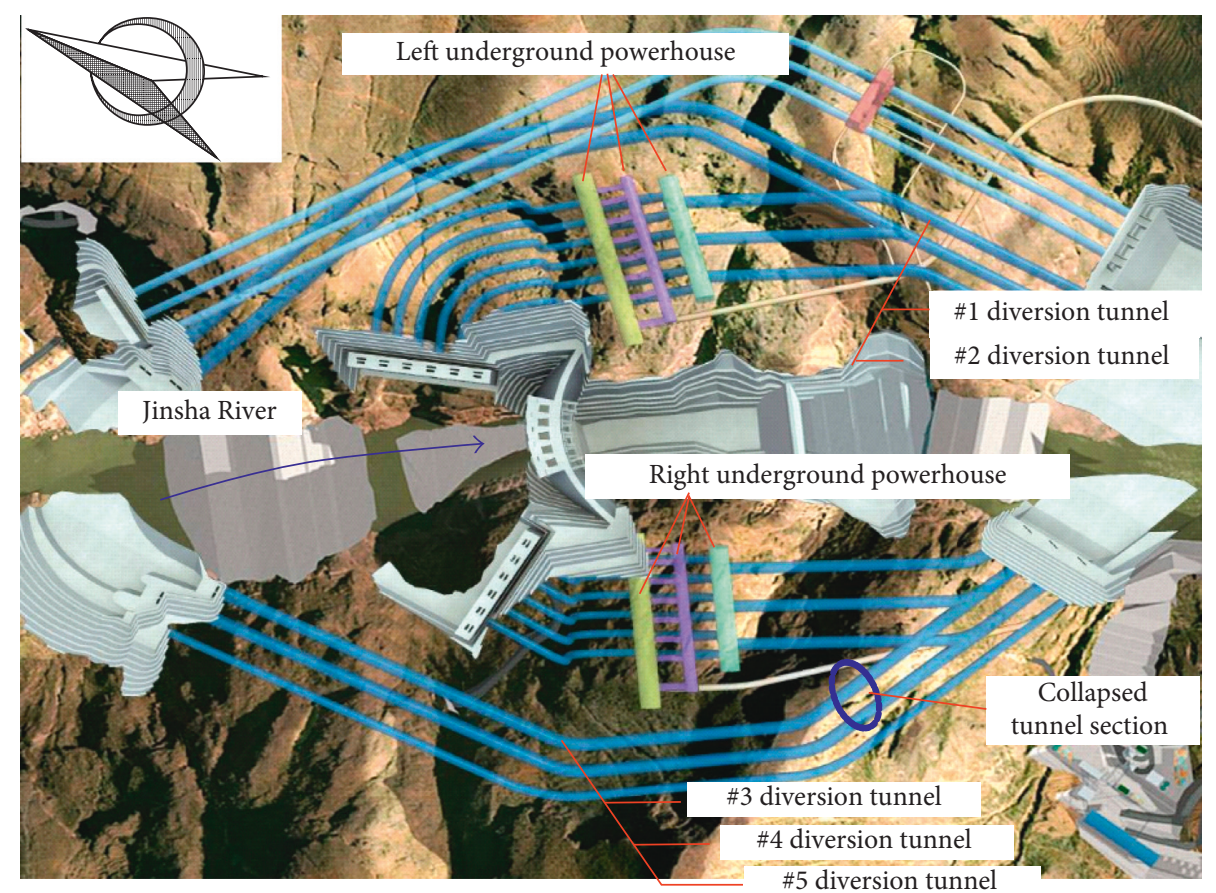

FIGURE 5: Layout of diversion tunnels of the Wudongde hydropower station [13].

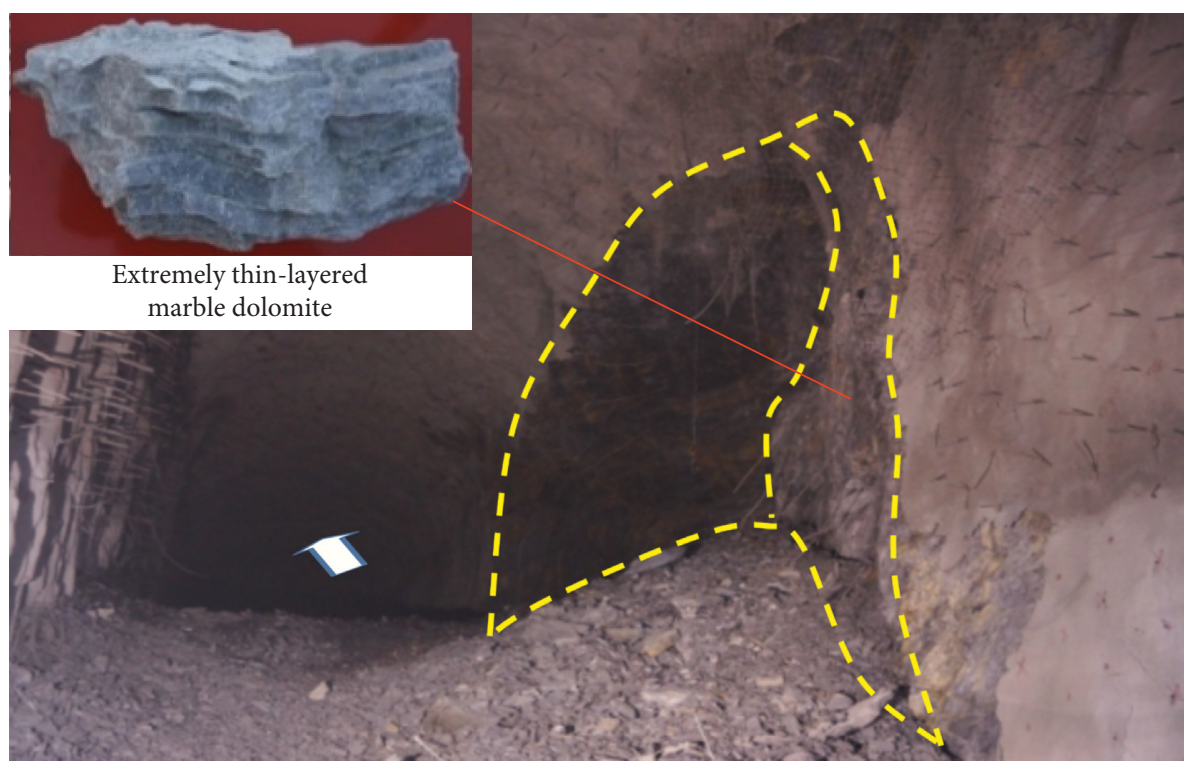

Figure 6: Collapse of tunnel section between stakes $\mathrm{K} 1+230$ and $\mathrm{K} 1+270$ in the \#3 diversion tunnel.

directions were approximately 3.78 $\mathrm{MPa}$ and $4.54 \mathrm{MPa}$, respectively. Considering the lack of timely support in the actual construction process, the equivalent treatment of stress relief was adopted in the simulation. According to the actual conditions and monitoring data, as well as the numerical feedback analysis of the stability of the surrounding rock mass of the Wudongde diversion tunnel [14], the stress relief coefficient was finally selected to be 0.75 ; that is, counterforces which are 0.25 times of those of the grid nodes were applied to the grid nodes after excavation to reflect the hysteresis of the deformation release of the surrounding rock mass.
4.3. Mechanical Parameters of the Surrounding Rock Mass. To ensure the reliability of the analysis results, the mechanical parameters of the Aniso-soft model were obtained by the intelligent back-analysis method $[15,16]$. This was based on the deformation increment during the step excavation of other tunnel sections with the same surrounding rock mass and the collapse depth of the left spandrel of these tunnels during the excavation of the first layer (without timely support). Firstly, the sensitivity analysis shows that the parameters that are most sensitive to deformation failure are $E_{1}$, $E_{3}, c_{\mathrm{m}}, c_{\mathrm{b}}$, and $\varphi_{\mathrm{b}}$. Then, these parameters are back-analysed 


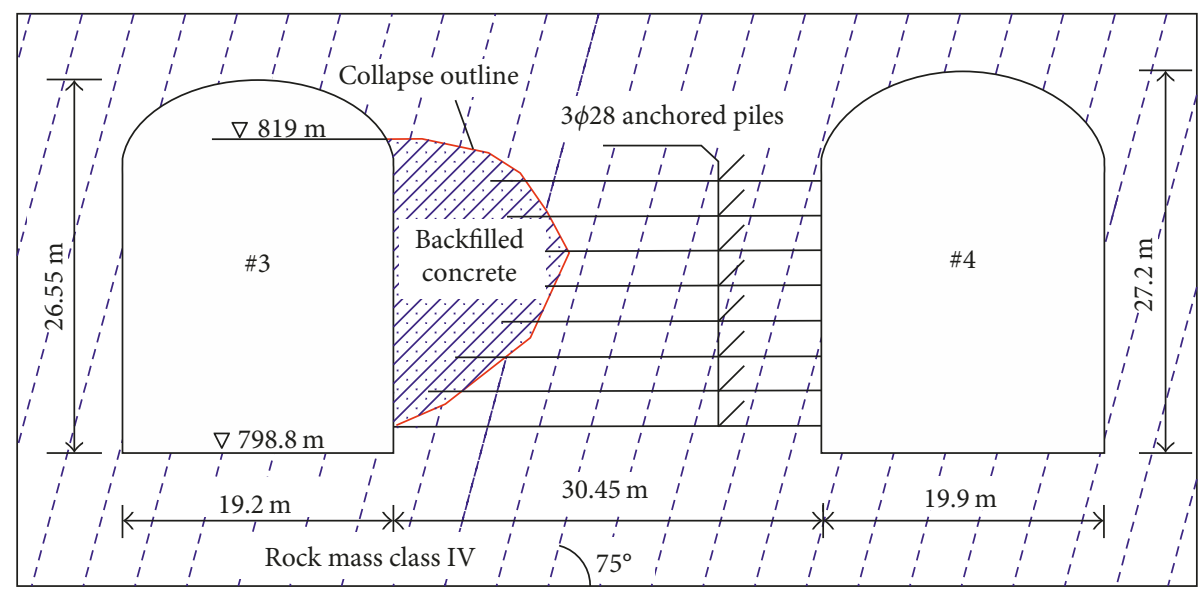

FIGURE 7: Emergency reinforcement measure of the midpartition at the collapse site.

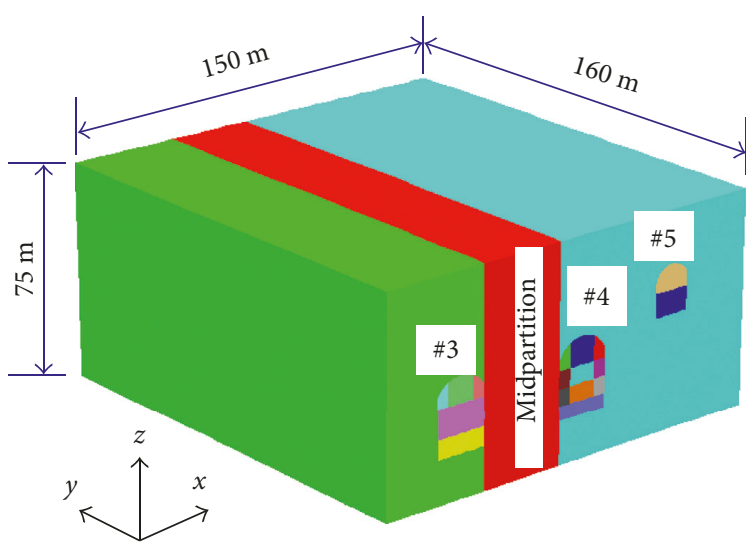

(a)

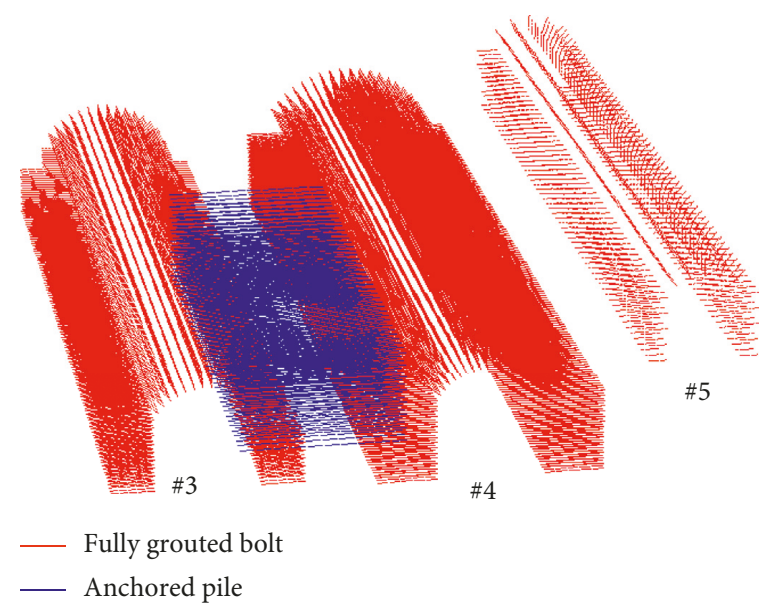

(b)

FIGURE 8: Geometric model of tunnel excavation (peripheral mountain not displayed) and support structure model: (a) tunnel excavation model and (b) support structure model.

TABle 2: Parameters of fully grouted bolt and anchored pile.

\begin{tabular}{lcc}
\hline & \multicolumn{2}{c}{ Values } \\
Parameters & $\begin{array}{c}\text { Fully } \\
\text { grouted } \\
\text { bolt }\end{array}$ & $\begin{array}{c}\text { Anchored } \\
\text { pile }\end{array}$ \\
\hline Cross-sectional area of cable $\left(\mathrm{m}^{2}\right)$ & $6.16 E-4$ & $5.54 E-3$ \\
Elastic modulus of cable $(\mathrm{GPa})$ & 210 & 210 \\
Grout exposed perimeter $(\mathrm{m})$ & 0.06 & 0.116 \\
Grout stiffness per unit length $(\mathrm{N} / \mathrm{m} / \mathrm{m})$ & $1.0 E+7$ & $1.0 E+7$ \\
Grout cohesive strength $(\mathrm{N} / \mathrm{m})$ & $1.0 E+6$ & $2.0 E+6$ \\
Grout friction angle $\left(^{\circ}\right)$ & 30.0 & 30.0 \\
Tensile yield strength of cable $(\mathrm{N})$ & $2.22 E+5$ & $2.0 E+6$ \\
\hline
\end{tabular}

by using the evolutionary neural network algorithm, and the results are shown in Table 3. Figure 10 shows the isolines for the point safety factor and collapse of the rock mass around the section at stake $\mathrm{K} 0+310$ after the excavation of the first layer of the \#4 diversion tunnel. It can be observed from the figure that the isolines for the point safety factor of the surrounding rock mass of the tunnel (Fos $=0.9)$ can effectively outline the collapse of the left spandrel of the

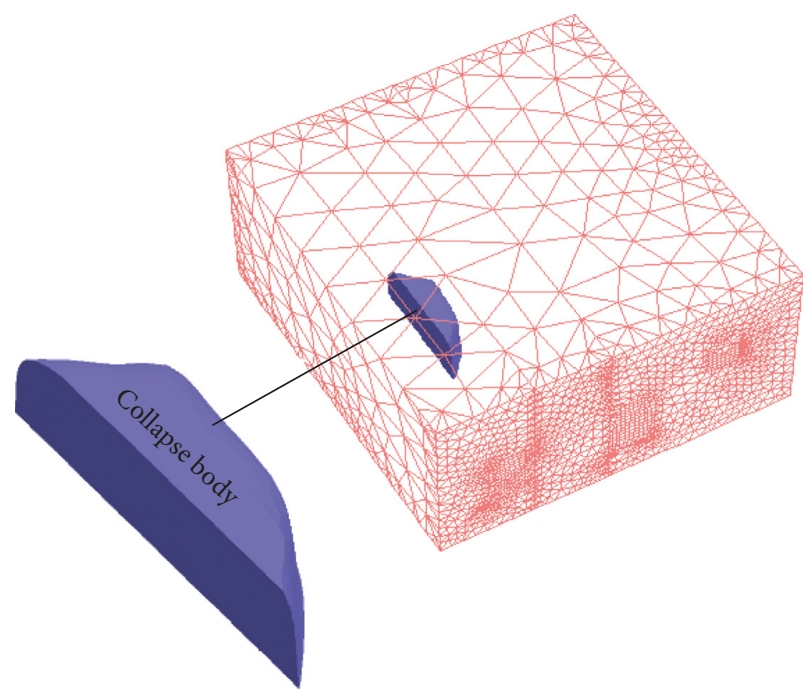

FIgURE 9: Collapse body and its position in the mesh model of the collapsed tunnel section. 
TABLE 3: Mechanical parameters of the surrounding rock mass and backfilled concrete.

\begin{tabular}{lccccccccccccccc}
\hline & $\begin{array}{c}E_{1} \\
(\mathrm{GPa})\end{array}$ & $\begin{array}{c}E_{3} \\
(\mathrm{GPa})\end{array}$ & $\begin{array}{c}G_{13} \\
(\mathrm{GPa})\end{array}$ & $v_{12}$ & $v_{13}$ & $\begin{array}{c}\psi_{\mathrm{m}} \\
\left(^{\circ}\right)\end{array}$ & $\begin{array}{c}\sigma_{\mathrm{m}}^{\mathrm{t}} \\
(\mathrm{MPa})\end{array}$ & $\begin{array}{c}c_{\mathrm{m}} \\
(\mathrm{MPa})\end{array}$ & $\begin{array}{c}\varphi_{\mathrm{m}} \\
\left({ }^{\circ}\right)\end{array}$ & $\begin{array}{c}c_{\mathrm{b}} \\
(\mathrm{MPa})\end{array}$ & $\begin{array}{c}\varphi_{\mathrm{b}} \\
\left({ }^{\circ}\right)\end{array}$ & $\begin{array}{c}\beta \\
\left({ }^{\circ}\right)\end{array}$ & $\begin{array}{c}\alpha \\
\left({ }^{\circ}\right)\end{array}$ & $\begin{array}{c}\psi_{\mathrm{b}} \\
\left({ }^{\circ}\right)\end{array}$ & $\begin{array}{c}\sigma_{\mathrm{b}}^{\mathrm{t}} \\
(\mathrm{MPa})\end{array}$ \\
\hline $\begin{array}{l}\text { Surrounding rock } \\
\text { mass }\end{array}$ & 2.4 & 1.8 & 0.75 & 0.30 & 0.33 & 10 & 1.0 & 2.0 & 45 & 0.1 & 30 & 75 & 60 & 6 & 0.2 \\
Backfilled concrete & 30 & 30 & 12 & 0.25 & 0.25 & 10 & 2.0 & 2.2 & 45 & 2.2 & 45 & 75 & 0 & 10 & 2.0 \\
\hline
\end{tabular}

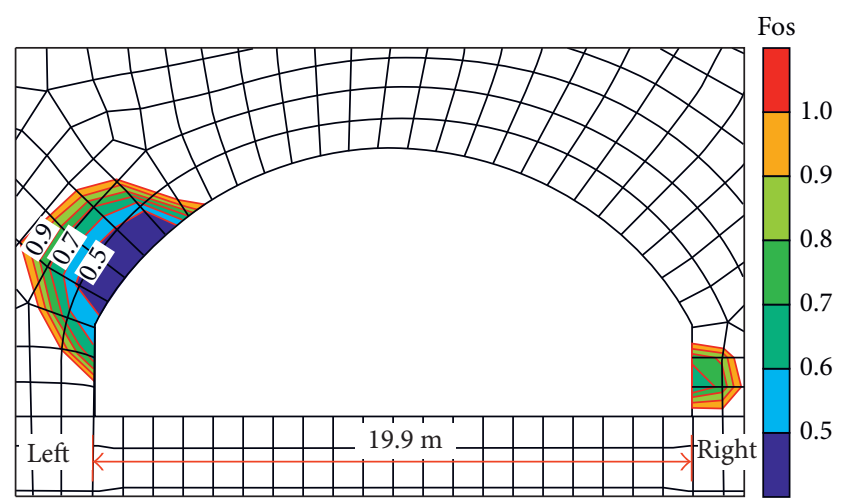

(a)

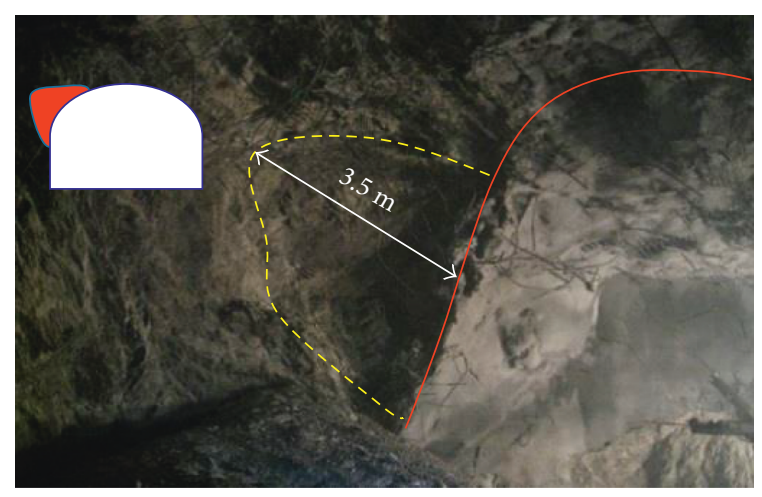

(b)

FIGURE 10: Isolines for the point safety factor and collapse of the rock mass around the section at stake K $0+310$ after the excavation of the first layer of the \#4 diversion tunnel: (a) isolines for the point safety factor and (b) collapse of the left spandrel.

tunnel. The pattern is close to that of the actual collapse profile, verifying the reliability of the mechanical parameters of the surrounding rock mass adopted in this simulation. This also indicates that it is feasible to evaluate the safety state of engineering layered rock masses by using the point safety factor.

To favor the calculation of point safety factors, the Aniso-soft model is also used to represent the properties of backfilled concrete, which is as an isotropic material. The parameters for the Aniso-soft model of backfilled concrete have the same values in the directions parallel and normal to the bedding plane. Its elastic modulus and Poisson's ratio are selected according to Chinese National Standard GB/T 50010-2010 [17], and the other parameters are empirical values (Table 3 ). In addition, taking into account the support structure for improving the integrity of the surrounding rock mass and further enhancing its strength, as well as referring to the recommendations of Zhu et al. [18], the internal frictions of the interlayered rock and the bedding plane after reinforcement both increased by $5^{\circ}$, and the cohesion of the interlayered rock after reinforcement increased by $0.5 \mathrm{MPa}$.

4.4. Analysis and Verification of Results. Figure 11 shows the isolines for the point safety factor of the rock mass around the midsection in the collapse tunnel section before collapse. It can be observed from the figure that there is a wide yielded and failed zones in the surrounding rock mass of the tunnel, and the zones where the point safety factor is less than 1.0 in the \#3 and \#4 diversion tunnels (the zone framed by red dotted lines) are nearly connected. Hence, there is a risk of large-scale collapse. The reason is that the extremely thinlayered marble dolomite is a type of rock mass sensitive to excavation disturbance. The bedding planes open, and the rock mass may become a plate-type structure after the stress in the normal direction of the bedding plane is released, which leads to the sharp decrease in the cohesion of the bedding planes. With the gradual progress of excavation, the degree of stress concentration of some zones, such as the left spandrel and the lower part of the right-side wall, increases. For the rock mass at the left spandrel, the stress concentration may cause the plates to buckle, collapse, and disintegrate. For the rock mass in the stress concentration zone on the right-side wall, two possible failure modes may occur: (1) some rock plates become cantilever slabs, breaking at the fixed end and sliding along the bedding planes, and (2) some rock plates become plates fixed at both ends; due to the poor bending strength under the end loads, the plates buckle, collapse, and disintegrate. Moreover, the failure process has obvious aging characteristics. Its failure is not caused by the rheology of the interlayered rocks and the bedding planes, but by the rheology of the rock mass structure. Therefore, timely support after the excavation is an effective measure for ensuring the stability of the surrounding rock mass, such as extremely thin-layered marble dolomite.

Figure 12 shows the isolines for the point safety factor of the rock mass around the midsection in the collapse tunnel section after the collapse. It can be observed from the figure that the zones where the point safety factor is less than 1.0 for the midpartition of the collapsed tunnel sections in the \#3 and \#4 diversion tunnels (the zone is framed by red dotted lines) are nearly connected, indicating that the thinner midpartition is close to failure after the occurrence of collapse in this zone. If the midpartition is not reinforced in time, it is likely to further collapse under subsequent excavation disturbances, thereby endangering the overall stability of this tunnel section. 


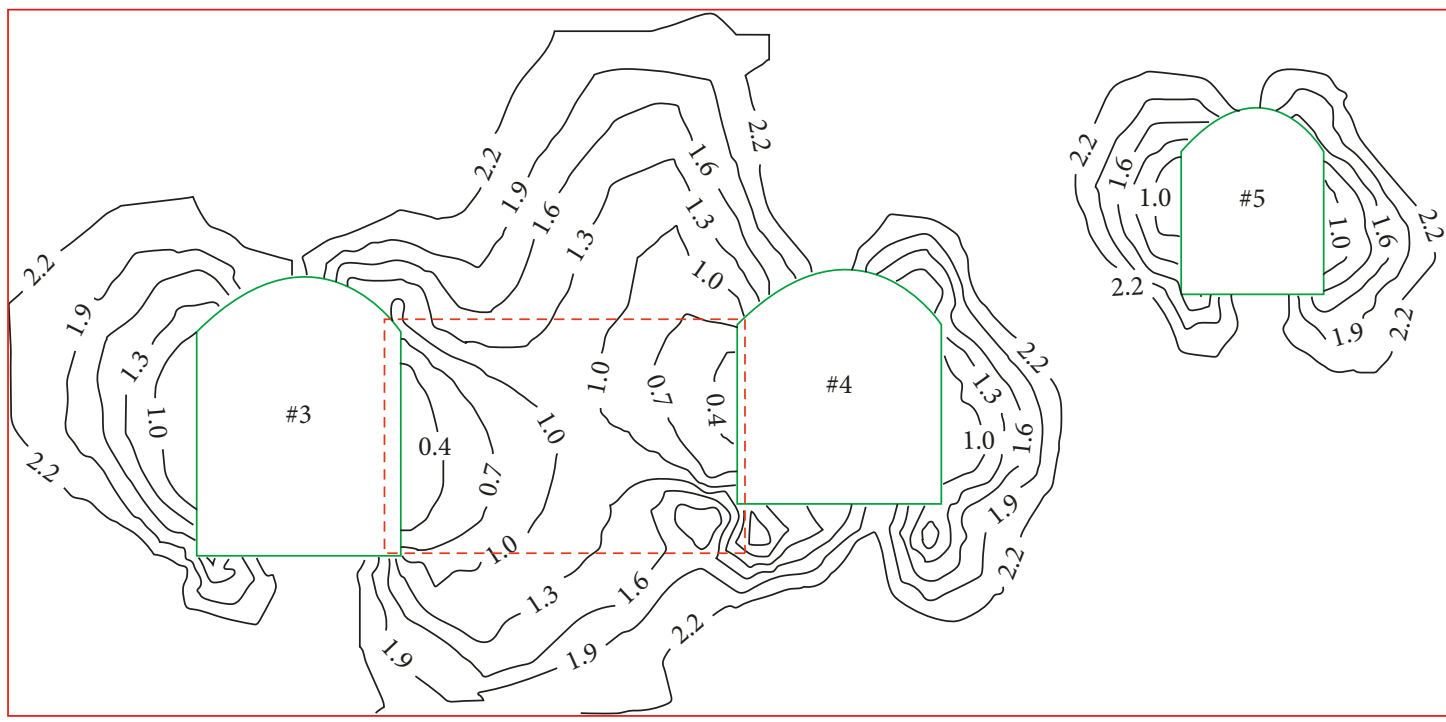

FIGURE 11: Isolines for the point safety factor of the rock mass around the midsection in the collapse tunnel section before collapse.

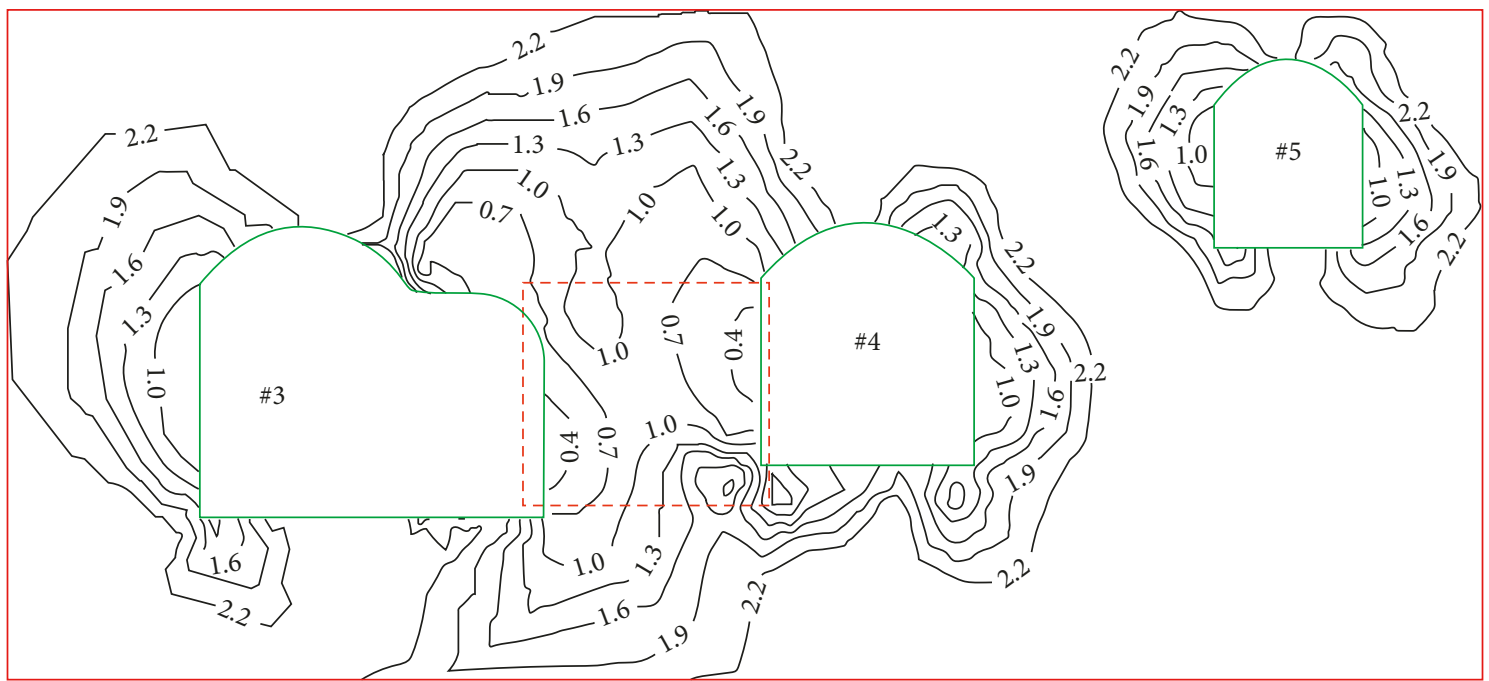

FIGURE 12: Isolines for the point safety factor of the rock mass around the midsection in the collapse tunnel section after collapse.

Figure 13 illustrates the isolines for the point safety factor of the rock mass around the midsection in the collapse tunnel section after the reinforcement. It can be observed from the figure that the point safety factor for the backfilled concrete zone is much greater than 1.0 (2.4), and it has effectively obstructed the potential cut-through trend of the yielded zone after the collapse of the midpartition. This indicates that, after the reinforcement measures are adopted, the surrounding rock mass of this tunnel section has a higher safety degree, and the emergency measures are effective. It should be pointed out that a wide loosened zone is inevitable because of the following two reasons: (1) because the quality of the surrounding rock mass in the tunnel section is poor, its deformation and looseness occur immediately after excavation, and (2) because the reinforcement construction is restricted by various factors, it is difficult to achieve a large-scale advance reinforcement or immediate reinforcement. However, when the extent of the support reinforcement is greater than that of the loosened zone, local collapse and falling can be effectively prevented. Therefore, in addition to reinforcing the collapsed tunnel section, other tunnel sections with the same type of surrounding rock mass should also be reinforced. The depth and extent of the reinforcement zone can be determined according to the zone where the point safety factor is less than 1.0.

Figure 14 shows displacement-time curves of the multipoint displacement meter setup in the vicinity of the midpartition (stake $\mathrm{K} 1+260)$ in the reinforced tunnel section with emergency measures. Although the full displacement-time curve of the monitoring points during excavation and reinforcement cannot be given due to the fact that the multipoint displacement meter is installed during the reinforcement construction, the stability of the reinforced tunnel can still be judged by the convergence trend of these curves of the monitoring points at different 


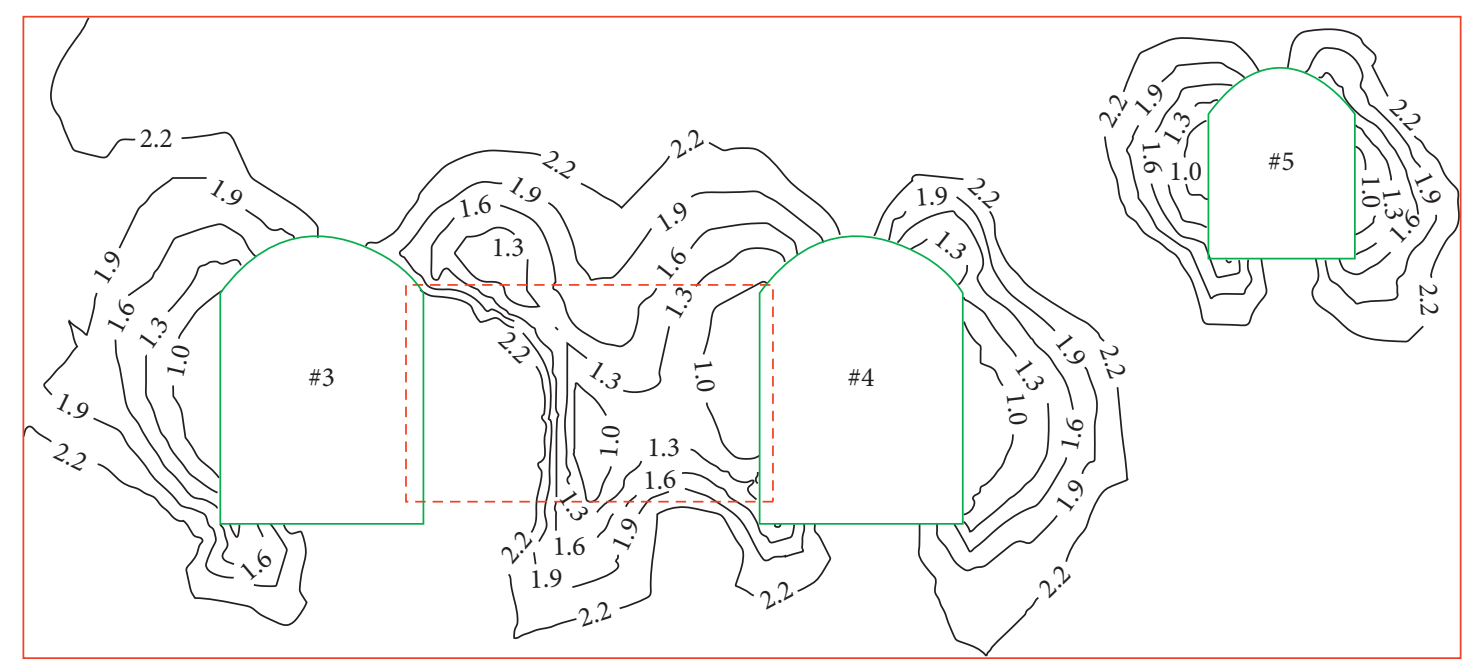

FIGURE 13: Isolines for the point safety factor of the rock mass around the midsection in the collapse tunnel section after the reinforcement.

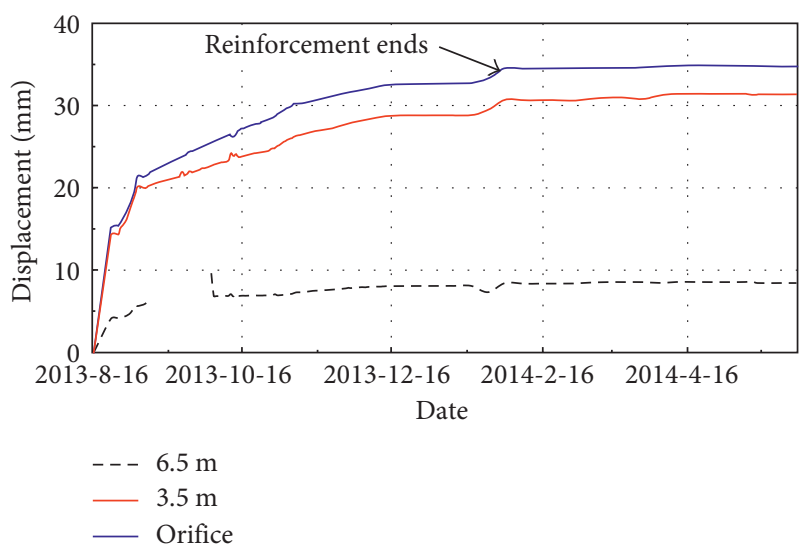

Figure 14: Convergence curve of the multipoint displacement meter setup when conducting the emergency reinforcement of the midpartition at stake $\mathrm{K} 1+260$.

depths. It can be observed that the deformation of the surrounding rock mass tends to converge after the application of emergency reinforcement measures, indicating that the surrounding rock mass is in a stable state, which also demonstrates the effectiveness of the reinforcement measure.

\section{Conclusions}

(1) The point safety factor of a layered rock mass, which was established based on a transversely isotropic mechanical model, is the smallest value between the point safety factors of the interlayered rock and the bedding plane. The point safety factor effectively reflects the fact that a rock mass always fails along or across its weakest component. It provides a reasonable quantitative basis for the control of the stability of the surrounding rock mass during excavation and reinforcement of the underground engineering within the layered rock mass.
(2) A wide potentially unstable zone where the point safety factor is less than 1.0 was still in the remaining midpartition of the collapsed tunnel section between the \#3 and \#4 diversion tunnels of the Wudongde hydropower station. The collapse led to the thinning of the midpartition, resulting in the potential unstable zones being nearly connected. If the remaining midpartition is not reinforced in time, it may collapse as a whole, thus endangering the overall stability of the tunnel.

(3) After the emergency reinforcement measure with two-ended anchored piles and concrete backfill to the midpartition of the collapsed tunnel section, the point safety factor of the midpartition (much larger than 1.0) was significantly improved, indicating that the emergency reinforcement measure was effective and significantly enhanced the safety degree of the surrounding rock mass in this tunnel section. Moreover, the deformation of the surrounding rock mass tends to converge after the reinforcement, which further demonstrates the effectiveness of the reinforcement measure.

\section{Data Availability}

The data used to support the findings of this study are available from the corresponding author upon request.

\section{Conflicts of Interest}

The authors declare that they have no conflicts of interest.

\section{Acknowledgments}

This research was funded by the State Key Research Development Program of China under Grant no. 2016YFC0600707, by the Open Project of Guangxi Key Laboratory of Geomechanics and Geotechnical Engineering under Grant no. 15KF-03, and by the Fundamental Research Funds for the 
Central Universities (Wuhan University of Technology) under Grant no. 2017IVA047. The research was also supported by the Wudongde Project Construction Department, China Three Gorges Projects Development Co., Ltd.

\section{References}

[1] X. D. Kou, W. Y. Zhou, and R. Q. Yang, "Stability analysis on the high slopes of three-gorges shiplock using FLAC3D," Chinese Journal of Rock Mechanics and Engineering, vol. 20, no. 1, pp. 6-10, 2001.

[2] T. Yang, D. P. Zhou, H. M. Ma et al., "Point safety factor method for stability analysis of landslide," Rock and Soil Mechanics, vol. 31, no. 3, pp. 972-975, 2010.

[3] S. C. Li, S. C. Li, and B. S. Xu, "Minimum safety factor method for stability analysis of surrounding rockmass of tunnel," Rock and Soil Mechanics, vol. 28, no. 3, pp. 549-554, 2007.

[4] M. L. Lin, C. F. Chung, F. S. Jeng et al., "The deformation of overburden soil induced by thrust faulting and its impact on underground tunnels," Engineering Geology, vol. 92, no. 3-4, pp. 110-132, 2007.

[5] C. Q. Zhang, H. Zhou, and X. T. Feng, "An index for estimating the stability of brittle surrounding rock mass: FAI and its engineering application," Rock Mechanics and Rock Engineering, vol. 44, no. 4, pp. 401-414, 2011.

[6] R. K. Goel, A. Swarup, and P. R. Sheorey, "Bolt length requirement in underground openings," International Journal of Rock Mechanics \& Mining Sciences, vol. 44, no. 5, pp. 802-811, 2007.

[7] H. Kumar, D. Deb, and D. Chakravarty, "Design of crown pillar thickness using finite element method and multivariate regression analysis," International Journal of Mining Science and Technology, vol. 27, no. 6, pp. 955-964, 2017.

[8] T. T. Wang, H. L. Ma, C. H. Yang et al., "Safety evaluation of salt cavern gas storage close to an old cavern," International Journal of Rock Mechanics \& Mining Sciences, vol. 83, pp. 95-106, 2016.

[9] D. P. Xu, X. T. Feng, D. F. Chen et al., "Constitutive representation and damage degree index for the layered rock mass excavation response in underground openings," Tunnelling and Underground Space Technology, vol. 64, pp. 133-145, 2017.

[10] Itasca Consulting Group Inc., FLAC3D (Fast Lagrangian Analysis of Continua) Theory and Background, Itasca Consulting Group, Minneapolis, MN, USA, 2005.

[11] Y. M. Tien, M. C. Kuo, and C. H. Juang, "An experimental investigation of the failure mechanism of simulated transversely isotropic rocks," International Journal of Rock Mechanics and Mining Sciences, vol. 43, no. 8, pp. 1163-1181, 2006.

[12] S. G. Lekhnitskii, Theory of Elasticity of an Anisotropic Body, Mir Publishers, Moscow, Russia, 1981.

[13] X. Q. Niu, B. X. Shi, and Y. H. Weng, "Feasibility study report of the Wudongde hydropower station on the Jinsha River, first paper: comprehensive statement," Report No. S139F10-1147, Changjiang Institute of Survey Planning Design and Research, Changjiang Water Resources Commission, Wuhan, China, 2011.

[14] D. P. Xu, Q. Jiang, and D. F. Chen, "Dynamic feedback analysis of stability and optimization of excavation and support schemes of the diversion tunnels at the Wudongde hydropower station," Report No. IRSM-2014-170, Institute of Rock and Soil Mechanics, Chinese Academy of Sciences, Wuhan, China, 2014.
[15] X. T. Feng, Z. Q. Zhang, and Q. Sheng, "Estimating mechanical rock mass parameters related to the Three Gorges Project permanent shiplock using an intelligent displacement back analysis methods," International Journal of Rock Mechanics and Mining Sciences, vol. 37, no. 7, pp. 1039-1054, 2000.

[16] X. T. Feng, H. B. Zhao, and S. J. Li, “A new displacement back analysis to identify mechanical geo-material parameters using integrated intelligent methodology," International Journal for Numerical and Analytical Methods in Geomechanics, vol. 28, no. 11, pp. 1141-1165, 2004.

[17] The National Standards Compilation Group of People's Republic of China, Chinese National Standard GB/T 50010-2010: Code for Design of Concrete Structures, China Architecture and Building Press, Beijing, China, 2015.

[18] W. S. Zhu, S. C. Li, and W. Z. Chen, Failure Mechanism and Anchorage Effect of Jointed Rock Mass and Its Engineering Application, China Science and Technology Press, Beijing, China, 2002. 


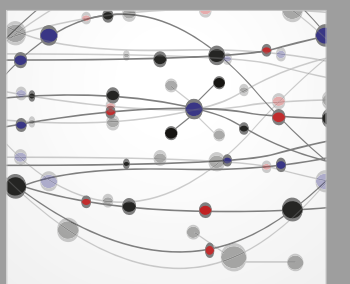

The Scientific World Journal
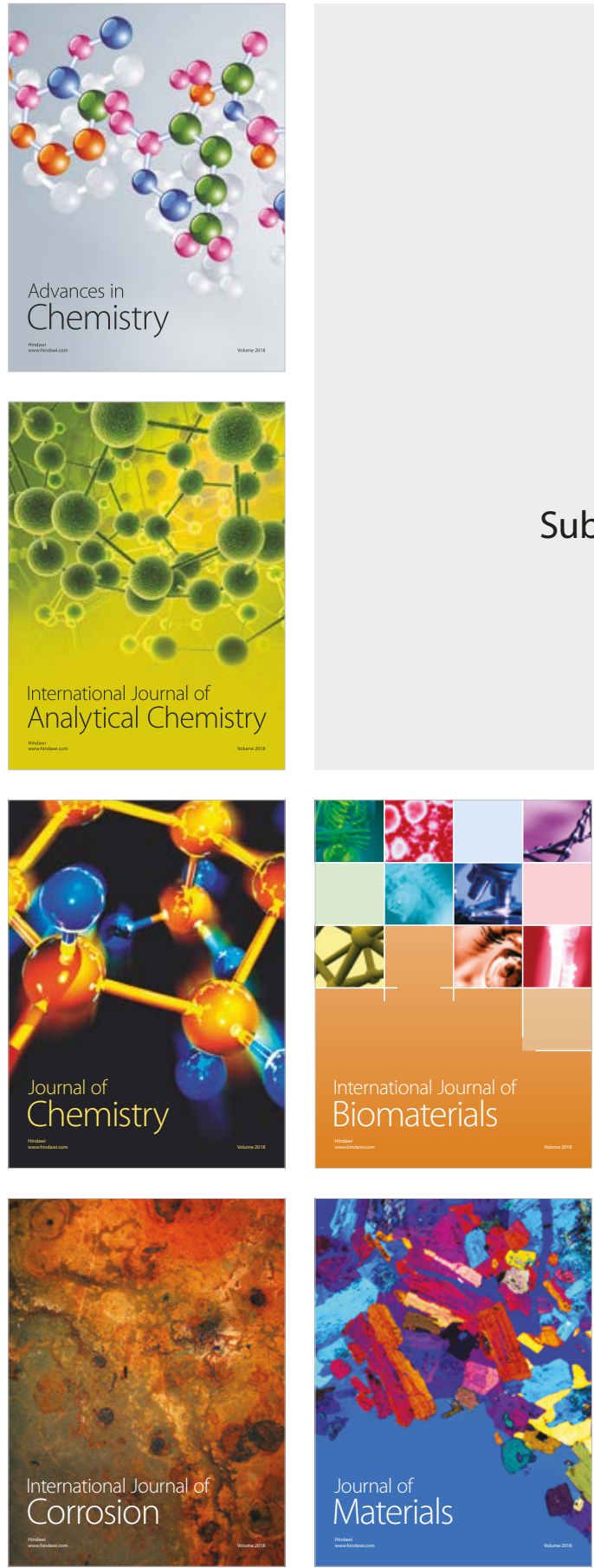

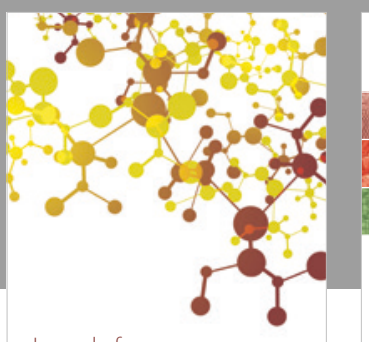

Journal of

Applied Chemistry
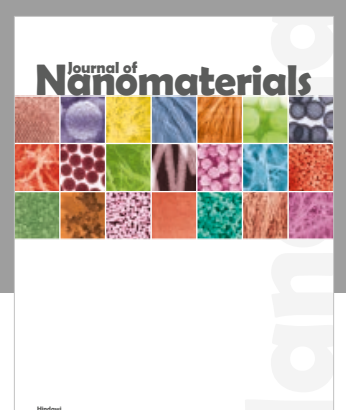

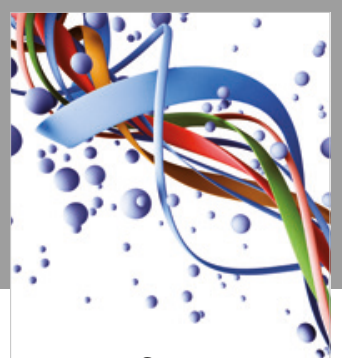

Scientifica

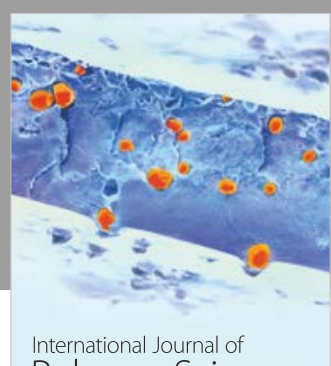

Polymer Science

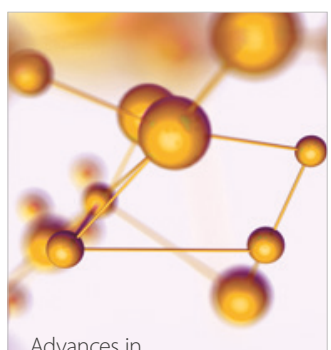

Physical Chemistry
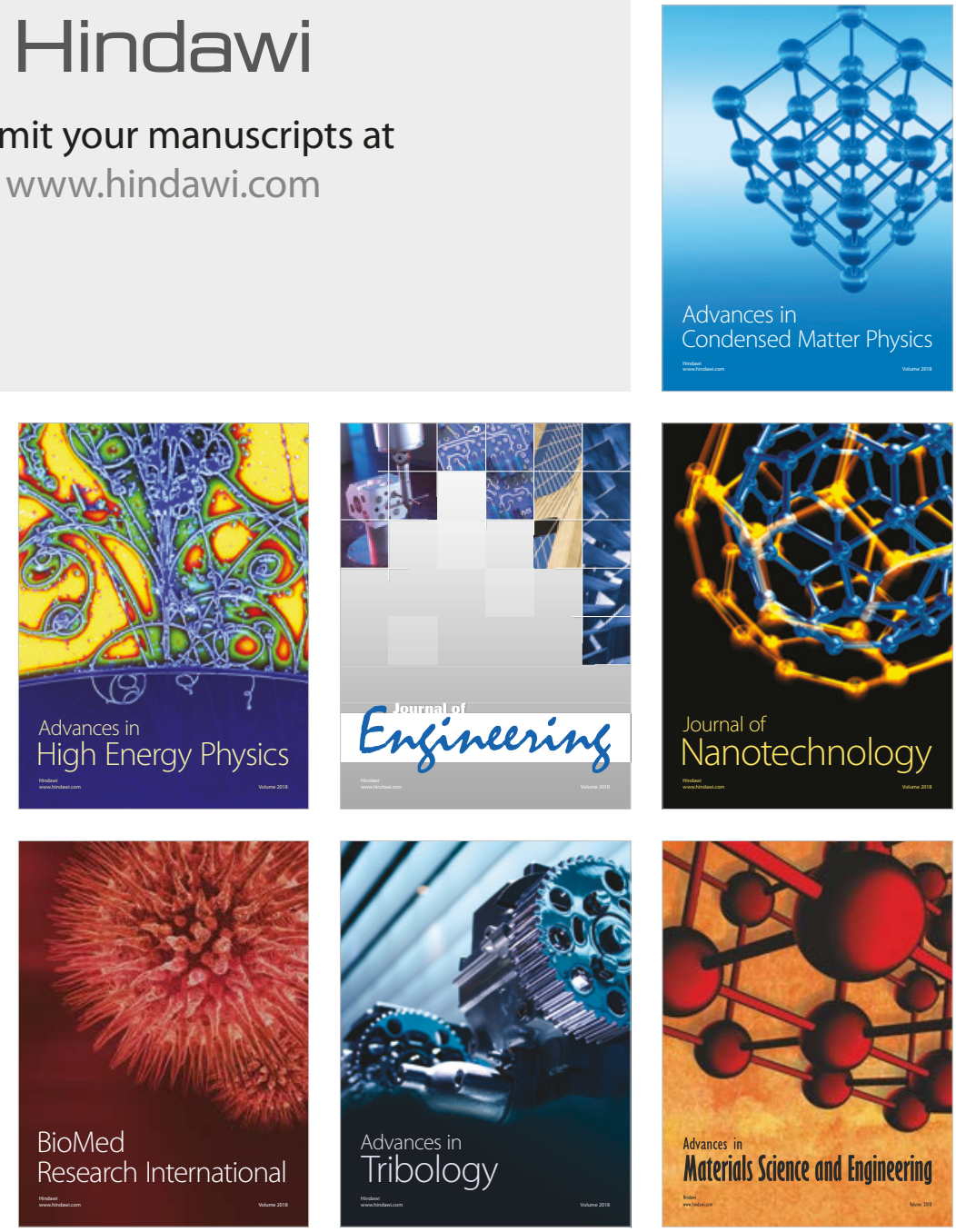